\title{
Content Summary
}

This book is a summary of what the author has experienced in teaching practices for dozens of years, 18 notes on electromagnetic theory together with one note on reflections and one note on teaching, 20 notes in all.

In particular, the book covers extensive contents ranging from the self-acting energy in electrostatic field, general electromagnetic inertia to electromagnetic symmetry. Questions are first raised, then discussed and finally refined to make a captivating summary of electromagnetic theory. In addition, the ideas, concepts, methods and engineering applications of electromagnetic theory are highlighted in the book.

These notes allow the author to communicate with vast numbers of electromagnetic workers equally and sincerely, to profess his own difficulties and doubts in learning and research and to advance his basic views on the development of electromagnetic theory.

The notes provide the author with an opportunity to share learning experience and lessons with many young teachers. In the book, the question-and-answer interview is more vocal and interactive.

The book is also a reference book for large numbers of graduate students, undergraduates and junior college students around the 1990s.

The book is suitable not only for teachers, graduate students and undergraduate students specializing in electronic information and communication at universities as a primary teaching book and reference book, but also for engineering and technical staff as a reference book. 
